\title{
TITLE
}

\section{INVOLVING CARERS IN THE TEACHING, LEARNING AND ASSESSMENT OF MASTERS STUDENTS}

\author{
Authors \\ ${ }^{*}$ Dr. Robert McSherry (RMcS) \\ Professor of Nursing and Practice Development \\ Dr. Sandra Duggan (SD) \\ Project Co-ordinator for User and Carer Involvement (2008-2014)
}

${ }^{*}$ Corresponding author

School of Health and Social Care, Teesside University, Middlesbrough, TS1 3BA, United Kingdom

Telephone: 00441642342972

Email: Robert.McSherry@tees.a.cuk

\section{Acknowledgements}

We would like to acknowledge the two carers, Shirley Duffield and Pat Rutherford, for their continued involvement in the programme without which we believe our students would have had a far less rich learning experience. We would also like to thank them for reading and commenting on this article prior to submission.

Word Count: 3053 


\title{
TITLE
}

\section{INVOLVING CARERS IN THE TEACHING, LEARNING AND ASSESSMENT OF MASTERS STUDENTS}

\begin{abstract}
Involving patients and carers in teaching, learning and assessment focuses the students on person-centred care by providing the opportunity to listen to, and reflect on, the perspective of patient and / or carer and also allows the students the opportunity to work in partnership with them to effect meaningful change. This paper presents an example at Teesside University where two informal carers have been involved as partners in the programme team of The Master of Arts in Advancing Practice over the past four years. In year two of the programme, the student is required to work within their organisation and governance policies to identify, implement and evaluate a practice development change project. Involving carers at critical points throughout the year has enriched, supported and challenged the students' learning. Evaluation has highlighted the role that carers can play in bringing a new dimension to the students' learning experience. The authors believe that direct involvement of this kind has much potential for other programmes in improving health and social care education which, in turn, will improve health and social care services.
\end{abstract}

Key Words: Carer Involvement, Public Participation, Postgraduate Education in Health Care, Nursing.

\section{Highlights}

- An example of direct involvement of informal carers in masters level education

- Involvement in developing and in assessing a change project

- Carers acting as collaborators and critical friends to the students 
- Involvement promotes a focus on patient-centred care

- Involvement enriches student learning

\section{BACKGROUND}

Recent cases in the United Kingdom (UK) exposing appallingly bad health care have led many to question the ethos and underlying values of our health care system. One such example occurred in a hospital in Mid Staffordshire. A report by the Healthcare Commission in 2009 stated that the mortality rate in this Trust was 'significantly high' suggesting that there were 'systemic problems' ( $p$ 123). The report also stated that 'A major concern was poor standards of nursing care' ( $p$ 123). The press (Guardian, 2013) estimated that 400-1200 patients died as a result of inadequate care. In similar vein, serious abuse of patients by staff was uncovered in Winterbourne View, a hospital providing care for people with learning disabilities (Department of Health, 2012). These cases have led to much debate, inquiries and subsequent moves by government, inspection bodies and health authorities to try to prevent this kind of poor practice from recurring.

The public inquiry, which followed the Mid Staffordshire Inquiry, found that the organisation had failed to 'listen sufficiently to its patients and staff or ensure the correction of deficiencies brought to the Trust's attention' (Mid Staffordshire National Health Service Foundation Trust Public Inquiry, 2013). The government response which was called 'Hard Truths: The journey to putting patients first' (Department of Health 2014) stated that 'listening to patients and the public and responding to what they say is at the heart of compassionate healthcare systems. Patients must be involved and given their say at every level of the system'. 
Kitwood (1997) and later Brooker (2007) had previously suggested that the delivery of safe, compassionate quality nursing care is dependent on 'person centred care' which encompass a broad range of values and approaches that places the lived experiences of patients and informal carers (family and / or significant loved ones) at its core. More widely, McSherry et al, (2012) suggest that listening and responding to both patient and staff experience is essential in creating an organisational culture and working environment in which excellence in practice can flourish.

Logically the focus on patient-centred care and its underlying values should begin right at the start of professional training and ideally should permeate all educational programmes for health and social care professionals. This has been acknowledged by the professional bodies such as the Health and Care Professions Council (HCPC) and the Nursing and Midwifery Council. The latter have promoted the involvement of patients in the education of nurses since the early 1990s making it mandatory in 2010 in pre-registration programmes (Nursing and Midwifery Council, Standard R5.1.2, 2010). The Berwick report on improving patient safety in England states strongly that the patient voice should be involved 'during the training of healthcare personnel' (Berwick, 2013). The report of the Willis commission in 2012 stated that 'Patient-centred care should be the golden thread that runs through all preregistration nursing education and continuing professional development.' Terry (2013) found that, in reality, there is considerable variation in involvement in nurse education but also pointed out the benefits of involvement include a more patient-centred approach, increased empathy and self-awareness. In relation to allied health professionals and social workers and following a rigorous consultation exercise, the HCPC published a standard (SET 3.17) stating that 'Service users and carers must be involved' in the programmes they regulate (HCPC, 2013, p32). 
It could be argued that involvement in postgraduate education may not be as beneficial as in pre-registration education because students are likely to be experienced practitioners. Alternatively, the experience can be seen as an opportunity to reinforce patient-centred values as well as the chance to interact with patients or carers as equals outside of the clinical environment and all its associated pressures, which is rarely the case in practice.

There is no doubt that involvement of patients and carers in higher education requires a shift in approach by teaching staff who may not be comfortable with the idea of coteaching. In addition, the organisational bureaucracy, funding, lack of support and resources can present barriers to involvement. In this article, we aim to share our experience of directly involving informal carers in the teaching, learning and assessment of students studying a Masters level programme.

\section{EXEMPLAR OF DIRECT PATIENT / CARER INVOLVEMENT IN A MASTER OF ARTS (MA) ADVANCING PRACTICE PROGRAMME}

The MA in Advancing Practice, which has been ongoing for the last 14 years, is designed to introduce students to robust methodologies to evaluate the effectiveness and efficiency of initiating and advancing change in practice. The entry criteria for the programme are that the student is working in health (primary or secondary care) or social care, has a first degree and/or equivalent qualification and has at least three years' relevant experience. Professions include nursing, midwifery, health visiting, social work, physiotherapy and occupational therapy with a variety of roles from junior to senior practitioners, consultant nurses, managers and specific leads 
for improvement, safety and practice development. Students may be working in the state, voluntary or independent sector. The length of service of students on the programme to date ranged from 3 years $-20+$ years. Student numbers are small (less than 10) due to the nature of the programme, funding restrictions and release time.

The programme is part-time over 3 years and in three stages (table 1). Several unique features are integrated into the programme, one of which is to offer the students the opportunity to draw on the experience(s) of carers to inform their proposed practice advancement. This feature, which was introduced 4 years ago when the programme was restructured and validated, is a commitment to improving the student learning experience by involving carers as much as possible in this part of the programme. This opportunity was facilitated at Teesside University by a well-developed infrastructure for patient (or 'service user') and carer involvement with members of the public regularly participating in the design, development and delivery of programmes at undergraduate and postgraduate levels in both health and social care. An ongoing strategy and a payment policy were well-embedded. In addition, a part-time coordinator (SD) post enables lecturers to engage with involvement safe in the knowledge that patients and / or carers with the most appropriate experience for each activity will be selected and supported and that the necessary practicalities will be arranged. Consequently two people, who had originally come forward because of their role as 'informal' carers i.e. caring for a family member or a close friend, were invited to take part in this MA programme and then carefully prepared. Although their caring experience is the reason they became involved with the university, they also both have experience as patients. These two members of the public have now been involved with the programme for the last four years. 
The programme structure, illustrated in Table 1, shows that in Stage 1, the students undertake theoretical modules which include studying models of change.

\section{Insert Table 1 Here}

Involvement takes place in Stage 2 in the second year when students are required to develop a portfolio which aims to develop the critical thinking and decision-making skills to support the utilisation of a change process framework in order to advance an innovation in health and social care practice. Throughout the module, the carers are involved at regular and critical points as integral members of the programme and module teams (Figure. 1).

\section{Insert Figure 1 Here}

At the beginning of the module the carers are involved in the induction and in the students' project proposal and planning sessions. This ensures that the proposed practice development / service improvement change is patient-centred in idea and approach. Continuing involvement in the action learning sets ensures that the students keep on track and do not lose sight of the patient-centred care focus. The carers act as critical friends establishing a supportive relationship while ensuring that the patient perspective, caring values, beliefs and attitudes are kept at the forefront of the students' minds. The carers form part of the summative assessment team in that they are present at, and contribute to, the assessment of the final student presentations being fully involved in the determination of the marking. In addition, they are given access to the students' final portfolios and again involved in the discussion of the marking. In both assessments, the carers serve to assess and verify the patientcentred nature of the projects. 
Over the four year period since the module has run with its present structure, the carers have become increasingly accustomed to working together with the lecturer and the students. The carers are now more confident in challenging and questioning student ideas enabling students to develop feasible patient-centred projects while at the same time, the lecturer ensures that the projects are capable of meeting the academic criteria.

Over the years, the students have chosen a diverse range of topics for their change in practice project some of which have gained regional recognition for innovation and enterprise. The projects ranged from those where the carers could imagine that they might be directly affected as patients such as 'Patient Directed Rehabilitation' to those which were more indirectly focused on patients such as 'The Development of a “Learning Obstetric Emergencies” Training Programme'. In practice, the carers have been able to engage constructively with all the projects whether they were directly or indirectly focused on patient care.

\section{EVALUATION AND OUTCOMES}

On completion of the programme, students and carers are asked to complete an anonymous evaluation.

\section{$\underline{\text { Student evaluation }}$}

The end of year evaluation for the second year of the programme has consistently demonstrated that carer involvement has enriched the students' learning experience on several fronts. 
Firstly, the students stated that the interactive and informative nature of the learning and teaching strategy became a motivating tool. Sharing progress and challenges with the carers was found to be 'exciting and enlightening'.

Secondly, the importance of obtaining patient/carer feedback was recognised as equally important as that from the academic module / programme team enabling students to gain the perspective of the user/carer, 'a different angle', rather than that of a professional. Students found that the carers provided both support and inspiration.

Thirdly, the direct involvement of carers within the module was welcomed and acknowledged as a unique aspect of the module.

Significantly, during the four years of involvement in the module to date, students have overwhelmingly endorsed the approach with all feedback being positive in the evaluations.

\section{Carer Evaluation}

The two carers, whose primary motivation was to improve future health care, felt that their input focused the students on change for patient benefit while recognizing the limitations of the system:

'...ensuring that the student initiates changes in practice that will be of benefit to patients and carers and meets organizational needs.'

Their belief was that the bringing of their own real, recent and local experience could provide an additional and significant perspective to the students' learning: 
'The presence of users/carers keeps things in perspective and gives the students the opportunity to see things from the 'other side' and judge reactions to their proposals.'

'This has brought a new dimension to the learning experience of the students.'

'This approach opens the minds of students to the whole patient experience.'

The carers regarded themselves as critical friends by

'providing an appropriate sounding board for their [students'] own ideas and improvements.'

\section{CONCLUSIONS AND IMPLICATIONS}

The use of case studies and/or exemplars of best practice are important for sharing and learning from events, situations and experiences both good and not so good (Parliamentary and Health Service Ombudsman 2015, West et al, 2012, Popil, 2011). Case studies are an ideal way of enhancing critical thinking, reflection and in promoting safe, quality evidence-based care. This can be achieved by focusing on an integrated approach to care as experienced by all those involved in the care processes and outcomes (McSherry and Proctor Childs, 2001).

This example has demonstrated that the direct engagement of carers in student education at Masters level integrates the lived experience, aims to ensure that change is person-centred and that the underlying core values are kept at the forefront of the students' thinking. Far from token involvement, the carers in this example worked together in genuine partnership with the lecturer and the students. In terms of Tew et al's (2004) Ladder of Involvement which spans level 1 (little or no involvement) to level 5 (full partnership), we believe that this is an example of full collaboration ( level 4). 
The literature frequently reports a lack of hard evidence on the impact of involvement on health and social care education or indeed practice (see for example, Rhodes, 2012). The authors suggest that this may be due to the complexity of demonstrating impact and the paucity of resources for doing so. In our admittedly small case study the students, the lecturer (RMcS), and the carers report their perception that involvement of the kind described here has significant benefits. The fact that the carers have continued their involvement is further evidence that they believe their input to be of value.

The collaborative involvement with carers described in this paper has potential for other programmes and can only improve the education and subsequent practice of health and social care professionals. Given the recent exposure of the failings in the delivery of patient-centred care in the UK, it would seem hard to justify not working with patients and / or carers in the design and delivery of health and social care education. Ideally this kind of involvement should be an integral part of all health and social care education.

\section{Acknowledgements}

To be inserted.

\section{Conflicts of interest}

None

\section{REFERENCES}


Berwick, D. 2013. A promise to learn - a commitment to act: Improving the safety of Patients in England. National Advisory Group on Safety of Patients in England, London.

Brooker, D. 2007. Person centred dementia care - making services better. Jessica Kingsley Publishers. London.

Department of Health 2012 Transforming Care: A national response to Winterbourne View Hospital . Department of Health Review: Final Report. December.

Department of Health 2014. Hard Truths: The Journey to Putting Patients First, HMSO, London.

Guardian. 2013. http://www.theguardian.com/society/2013/feb/06/mid-staffs-hospital$\underline{\text { scandal-guide }}$

Health and Care Professions Council (2013) Consultation on service user involvement in education and training programmes approved by the Health and Care Professions Council (HCPC) Summary of responses to the consultation and our decisions as a result. Available: http://www.hpc-

uk.org/assets/documents/10004110Consultationonserviceuserinvolvementineducatio nandtrainingprogrammes-consultationresponsesanddecisions.pdf. Accessed November, 2014

Healthcare Commission 2009 Investigation into Mid Staffordshire NHS Foundation Trust

March 2009. Commission for Healthcare Audit and Inspection.

Kitwood T. 1997. Dementia Reconsidered: The Person Comes First. Open University Press. 
McSherry, R., Pearce, P., Grimwood, K., McSherry, W. 2012. The pivotal role of nurse managers, leaders and educators in enabling excellence in nursing care. Journal of Nursing Management 20, 1, 7-19.

McSherry, R., Proctor-Childs, T. (2001) Promoting evidence-based practice through an integrated model of care: patient case studies as a teaching method Nurse Education in Practice 1, 19-26.

Mid Staffordshire NHS Foundation Trust Public Inquiry. 2013. Report of the Mid Staffordshire NHS Foundation Trust Public Inquiry Volume 3: Present and future NMC - Nursing and Midwifery Council. 2010. Standards for Preregistration Nursing Education.

http://www.nmc-

uk.org/Documents/Consultations/draft\%20standards\%20pre\%20reg.pdf Accessed November, 2014

Parliamentary and Health Service Ombudsman (2015) Report of the Health Service Ombudsmen on ten investigations into NHS care of older people - Case studies http://www.ombudsman.org.uk/care-and-compassion/case-studies [Accessed $21 / 07 / 205]$

Popil, N (2011) promoting critical thinking by using case studies as teaching method Nurse Education Today 31, 204-207.

Rhodes, C. 2012 User involvement in health and social care education: A concept analysis. Nurse Education Today, 32, 2 pp. 185-189.

Terry, J.M. 2013. The pursuit of excellence and innovation in service user involvement in nurse education programmes: report from a travel scholarship. Nurse Education in Practice 13, 202-6. 
Tew, J., Gell, G., Foster, S. 2004. Learning from experience. involving service users and carers in mental health education and training. A good practice guide. MHHE (Mental health in higher education) NHS (National Institute for Mental Health in England) Trent NHS Workforce Development Confederation.

West, C., Usher, K., Delaney, L, J. (2012) Unfolding case studies in pre-registration nursing education: Lessons learned Nurse Education Today 32, 576-580 Willis Commission 2012 Quality with Compassion: the future of nursing education. Royal College of Nursing. 
Table

Table 1. Master of Arts in Advancing Practice: Programme Structure

\begin{tabular}{|c|c|c|c|}
\hline & Term One & Term Two & Term Three \\
\hline \multirow{2}{*}{$\begin{array}{l}\text { Year } 1 \\
\text { Stage } \\
\text { One }\end{array}$} & \multirow{2}{*}{$\begin{array}{l}\text { Evidence Based } \\
\text { Practice Core } \\
\text { Module ( } 20 \text { Credits) }\end{array}$} & \multicolumn{2}{|c|}{$\begin{array}{l}\text { Health and Social Care in Context Module } \\
\text { (20 Credits) }\end{array}$} \\
\hline & & \multicolumn{2}{|c|}{$\begin{array}{l}\text { Advanced Personal Effectiveness in } \\
\text { Leadership ( } 20 \text { Credits) }\end{array}$} \\
\hline \multirow{2}{*}{$\begin{array}{c}\text { Year } 2 \\
\text { Stage } \\
\text { Two }\end{array}$} & $\begin{array}{l}\text { Designing a } \\
\text { Research Project } \\
\text { Core Module (20 } \\
\text { Credits) }\end{array}$ & & \\
\hline & \multicolumn{3}{|c|}{$\begin{array}{l}\text { Advancing Practice Through Portfolio (40 Credits) } \\
\text { WITH CARER INVOLVEMENT }\end{array}$} \\
\hline Year 3 & \multirow{2}{*}{\multicolumn{3}{|c|}{ Evaluating Practice Module (60 Credits) }} \\
\hline $\begin{array}{l}\text { Stage } \\
\text { Three }\end{array}$ & & & \\
\hline
\end{tabular}




\section{Figure}

Figure 1: Carer Involvement in the portfolio module

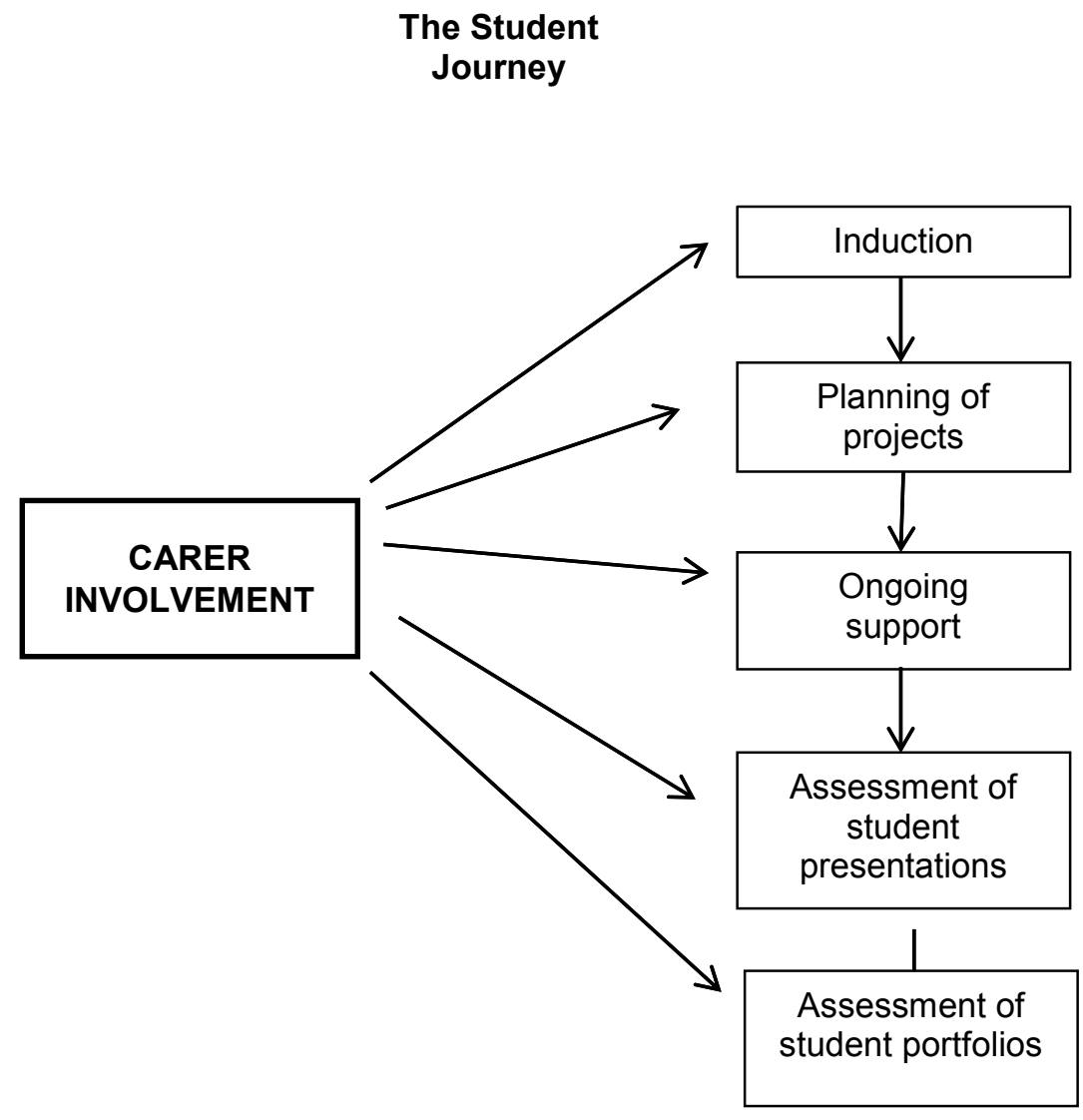

